\title{
Relation between Height Loss and Cardiovascular Disease: Data from Large Korean Cohort
}

\author{
Jeonggeun Moon \\ Gachon University College of Medicine \\ Pyung Chun Oh \\ Gachon University College of Medicine \\ Kyounghoon Lee \\ Gachon University College of Medicine \\ Ho-Jun Jang \\ Sejong General Hospital \\ Tae-Hoon Kim \\ CHA medical, Ilsan hospital \\ Sang-Don Park \\ Inha University Hospital \\ Sung Woo Kwon \\ Inha University Hospital \\ Min Gyu Kong \\ Soon Chun Hyang University Bucheon Hospital \\ Jon Suh \\ Soon Chun Hyang University Bucheon Hospital \\ Woong Chol Kang ( $\square$ kangwch@gilhospital.com ) \\ Gachon University College of Medicine
}

\section{Research Article}

Keywords: height loss, CVD, MACCE

Posted Date: April 4th, 2022

DOI: https://doi.org/10.21203/rs.3.rs-857902/v2

License: (c) (i) This work is licensed under a Creative Commons Attribution 4.0 International License. Read Full License 


\section{Abstract \\ Background}

Epidemiologic research has confirmed the inverse relationship between adult height and the incidence of cardiovascular disease (CVD). Height declines with age and its degree differs from person to person.

\section{Aim}

To investigate the association between height loss and CVD incidence.

\section{Methods}

In total, 127573 ethnically Korean patients were enrolled, and their height (cm) was monitored from 2002 to 2011 . The annual height loss (cm/year) was calculated as the difference between the first and the last height measurement within the observation period divided by the number of years. Patients were classified as Group 1 (reference group; height loss: 0 to $<0.3 \mathrm{~cm} /$ year; 102554 patients), Group 2 (height loss: 0.3 to $<0.6 \mathrm{~cm} /$ year; 17324 patients), or Group 3 (height loss: $\geq 0.6 \mathrm{~cm} /$ year; 7695 patients).

\section{Results}

The cumulative MACCE incidence rate was 3.6\% for Group 1, 4.5\% for Group 2, and 5.2\% for Group 3. Group 3 had a significantly higher incidence of MACCE than Group 1 (Group 1: hazard ratio $[\mathrm{HR}]=1.46,95 \%$ confidence interval $[\mathrm{Cl}]=1.32-1.62$; Group 2: $\mathrm{HR}=1.27,95 \% \mathrm{Cl}=1.17-1.37$ ). In the model adjusted for age, sex, comorbidities, income level, body mass index, smoking, and drinking status, the MACCE risk was 1.25 times higher in Group 3 than Group 1 (95\% $\mathrm{Cl}=$ 1.13-1.40).

\section{Conclusions}

The degree of height loss was independently associated with CVD occurrences in the Korean population.

\section{Introduction}

Growing evidence suggests that short stature is associated with cardiovascular disease (CVD) occurrence, ${ }^{1-4}$ although a rationale for this epidemiological finding remains unclear. Thus, adult height may be a non-modifiable CVD risk factor. The maximal stature of a given individual is determined in the late teen years. ${ }^{5}$ However, height declines during the normal aging process because of senile changes in the musculoskeletal system. ${ }^{6}$ The height loss degree varies from person to person based on the severity of osteoporosis or sarcopenia, which are the main contributors to a decrease in stature and have a known association with mortality. ${ }^{7-9}$ Hence, it is reasonable to hypothesize that the height loss degree affects the prevalence and prognosis of CVD independently from a single stature measurement. This topic was investigated once in elderly British men two decades ago, and the authors found that marked height loss ( $\geq 3 \mathrm{~cm}$ over the preceding two decades) was an independent CVD risk factor. ${ }^{10}$ However, adult height and height changes are influenced by age, sex, race, and socioeconomic status. Thus, data from different countries and eras are required to confirm this hypothesis. This study used a large Korean cohort to investigate the relationship between height loss and CVD.

\section{Methods}

\section{Study Samples}

The National Health Insurance Service (NHIS) of the Republic of Korea operates a mandatory public insurance program for all citizens and supports public health policy and research activities by developing and maintaining the National Health Information Database. ${ }^{11}$

Eligible subjects were ethnically Korean, older than 40 years, and underwent medical examinations in the Republic of Korea between January 01,2002 , and December 31, 2015; 332579 subjects were eligible. Patients were excluded for the following reasons: 89194 patients had only one height measurement, 57 164 patients had unreliable height data (i.e., an increasing height, a decrease of $\geq 20 \mathrm{~cm}$, or an annual decrease rate of $\geq 10 \mathrm{~cm} / \mathrm{year}$ ), 689 patients had missing demographic data during the observation period (2002 to 2011), 27599 patients had major adverse cardiac and cerebral events (MACCE) during the observation period, and 30360 patients died before 2012, which was the beginning of the MACCE monitoring period. As a result, 127573 patients were included in the analysis (Figure 1).

\section{Height and Height Loss Measurements}

Height was measured to the nearest $0.1 \mathrm{~cm}$ using a stadiometer in the subjects' upright position. The height decrease (cm) observation period was ten years (2002 to 2011). Each patient was included in the study at the time of the first height measurement. The annual height decrease rate (cm/year) was calculated as the difference between the first and the last height measurement within the observation period divided by the number of years. According to annual height 
decrease rate, patients were classified as Group 1 (reference; height loss: 0 to <0.3 cm/year; 102554 patients), Group 2 (height loss: 0.3 to <0.6 cm/year; 17 324 patients), or Group 3 (height loss: $\geq 0.6 \mathrm{~cm} /$ year; 7695 patients; Figure 1).

\section{Outcome Definitions and Monitoring}

The primary endpoint was MACCE occurrences between 2012 and 2015. MACCE was defined as cardiac death, non-fatal myocardial infarction (MI), unplanned hospitalization for heart failure (HF), and stroke based on the Korean Standard Classification of Diseases (KCD-7), which is based on the International Statistical Classification of Diseases and Related Health Problems. ${ }^{10}$ Stroke included ischemic and hemorrhagic origins. The demographic variables sex, age, income deciles ( $1^{\text {st }}$ to $10^{\text {th }}$ deciles), diabetes mellitus, dyslipidemia, hypertension, smoking (individuals who answered "I still smoke" to their smoking status were considered smokers), drinking (individuals who drank more than two times per week were considered drinkers), and body mass index [BMI $\left(\mathrm{kg} / \mathrm{m}^{2}\right)$ ] were collected. The BMI was calculated using body weight measured to the nearest $0.1 \mathrm{~kg}$ at the time of enrollment. For stratified analysis, those $\geq 60$ years were considered elderly (i.e., prone to height loss). Women $\geq 50$ years were arbitrarily defined as "menopausal" (after which height prominently decreases) based on the previously reported mean menopausal age of Korean women. ${ }^{12}$

\section{Statistical Analyses}

Differences in demographic characteristics based on the annual height decrease rate were evaluated using the chi-square test and the Kruskal-Wallis test. MACCE hazard ratios (HR) and $95 \%$ confidence intervals (Cl) were calculated based on the annual height decrease rate using a Cox proportional-hazard model adjusted for sex, age, income deciles, diabetes, dyslipidemia, osteoporosis, hypertension, smoking, drinking, and BMI. Factors affecting height decreases were analyzed using logistic regression and Kaplan-Meier survival curves and presented to estimate the cumulative MACCE incidence rates with time. Supplementary data presents the stratified analyses for the elderly and menopausal populations. All analyses were performed using the SAS 9.4 software (SAS Institute, Cary, NC, USA) at a statistical significance level of $a=0.05$.

\section{Results}

\section{Study Population Baseline Characteristics}

The overall number of height measurements was $4.1 \pm 2.0$ times and $4.3 \pm 2.0$ time for Group 1, 3.5 \pm 1.6 times for Group 2 , and $2.8 \pm 1.3$ times for Group 3 . The overall time gap between the first and the last height measurements was $69 \pm 28$ months and $73 \pm 27$ months for Group 1, $58 \pm 27$ months for Group 2 , and $39 \pm 27$ months for Group 3. Table 1 presents the demographic and clinical characteristic distributions based on the height decrease rate. There were 57 623 male patients (45.2\%) and 69950 female patients (54.8\%). Group 1 had the highest proportion of men, and Group 3 the highest proportion of women with a significant inter-group difference $(\mathrm{p}<0.0001)$. The highest proportion of patients was in their $50 \mathrm{~s}$, while the lowest was in their 90 s, with a significant intergroup difference $(p<0.0001)$. The highest proportion of patients was in the 10th deciles, and the lowest was in the 5 th deciles; this inter-group difference was also significant $(\mathrm{p}<0.0001)$. Overall, 48488 patients $(38.0 \%)$ had hypertension, and Group 2 had the highest proportion of patients with hypertension; the inter-group difference was significant $(p<0.0001)$. Further, 44619 patients $(35.0 \%)$ had dyslipidemia, and Group 1 had the highest proportion; the inter-group difference was also significant $(p<0.0001)$. In total, 20004 patients $(15.7 \%)$ were smokers, and Group 1 had the highest proportion; the inter-group difference was significant $(p=0.0485)$. Finally, Group 1 had the highest proportion of drinkers, and the inter-group difference was significant $(p<0.0001)$. 
Table 1

Study population baseline characteristics

\begin{tabular}{|c|c|c|c|c|c|c|c|c|c|c|}
\hline & \multirow{2}{*}{\multicolumn{2}{|c|}{ Total }} & \multicolumn{7}{|c|}{ Annual rate of height decrease ${ }^{\star \star}$} & \multirow[t]{4}{*}{ p-valuet } \\
\hline & & & Group 1 & & Group 2 & & Group 3 & & & \\
\hline & \multicolumn{2}{|c|}{$(N=127,573)$} & \multicolumn{2}{|c|}{$(N=102,554)$} & \multicolumn{2}{|c|}{$(\mathrm{N}=17,324)$} & \multicolumn{3}{|c|}{$(\mathrm{N}=7,695)$} & \\
\hline & $\mathbf{n}$ & (\%) & $\mathrm{n}$ & (\%) & $\mathbf{n}$ & (\%) & $\mathbf{n}$ & & (\%) & \\
\hline Sex & & & & & & & & & & $<.0001$ \\
\hline Male & 57,623 & $(45.2)$ & 48,053 & $(46.9)$ & 6,780 & (39.1) & 2,790 & & $(36.3)$ & \\
\hline Female & 69,950 & $(54.8)$ & 54,501 & $(53.1)$ & 10,544 & $(60.9)$ & 4,905 & & $(63.7)$ & \\
\hline Age & & & & & & & & & & $<.0001$ \\
\hline $40 \leq$ age $<50$ & 17,826 & $(14.0)$ & 13,359 & $(13.0)$ & 2,835 & $(16.4)$ & 1,632 & & $(21.2)$ & \\
\hline $50 \leq$ age $<60$ & 55,529 & $(43.5)$ & 47,056 & $(45.9)$ & 6,121 & (35.3) & 2,352 & & $(30.6)$ & \\
\hline $60 \leq$ age $<70$ & 34,497 & $(27.0)$ & 27,863 & (27.2) & 4,725 & (27.3) & 1,909 & & $(24.8)$ & \\
\hline $70 \leq$ age $<80$ & 17,434 & (13.7) & 12,826 & (12.5) & 3,129 & (18.1) & 1,479 & & (19.2) & \\
\hline $80 \leq$ age $<90$ & 2,264 & $(1.8)$ & 1,436 & $(1.4)$ & 507 & $(2.9)$ & 321 & & $(4.2)$ & \\
\hline $90 \geq$ age & 23 & $(0.0)$ & 14 & $(0.0)$ & 7 & $(0.0)$ & 2 & & $(0.0)$ & \\
\hline Income deciles & & & & & & & & & & $<.0001$ \\
\hline Lowest deciles & 11,399 & $(8.9)$ & 8,870 & (8.7) & 1,669 & $(9.6)$ & 860 & & (11.2) & \\
\hline Second deciles & 9,722 & $(7.6)$ & 7,619 & (7.4) & 1,437 & $(8.3)$ & 666 & & (8.7) & \\
\hline third deciles & 9,616 & $(7.5)$ & 7,609 & $(7.4)$ & 1,346 & $(7.8)$ & 661 & & $(8.6)$ & \\
\hline Fourth deciles & 9,372 & $(7.4)$ & 7,375 & $(7.2)$ & 1,306 & (7.5) & 691 & & $(9.0)$ & \\
\hline Middle deciles & 9,365 & (7.3) & 7,488 & (7.3) & 1,303 & (7.5) & 574 & & (7.5) & \\
\hline Sixth deciles & 11,135 & $(8.7)$ & 8,950 & (8.7) & 1,506 & $(8.7)$ & 679 & & $(8.8)$ & \\
\hline Seventh deciles & 12,455 & $(9.8)$ & 9,980 & $(9.7)$ & 1,734 & $(10.0)$ & 741 & & $(9.6)$ & \\
\hline Eighth deciles & 14,853 & (11.6) & 12,006 & (11.7) & 2,019 & (11.7) & 828 & & $(10.8)$ & \\
\hline Ninth deciles & 18,168 & (14.2) & 14,803 & (14.4) & 2,396 & (13.8) & 969 & & (12.6) & \\
\hline Highest deciles & 21,488 & $(16.8)$ & 17,854 & (17.4) & 2,608 & (15.1) & 1,026 & & (13.3) & \\
\hline \multicolumn{11}{|l|}{ Hypertension } \\
\hline Yes & 48,488 & $(38.0)$ & 38,632 & (37.7) & 6,828 & (39.4) & 3,028 & (39.4) & $<.0001$ & \\
\hline No & 79,085 & $(62.0)$ & 63,922 & $(62.3)$ & 10,496 & $(60.6)$ & 4,667 & $(60.7)$ & & \\
\hline \multicolumn{10}{|l|}{ Diabetes mellitus } & \multirow[t]{3}{*}{0.0769} \\
\hline Yes & 29,468 & $(23.1)$ & 23,554 & $(23.0)$ & 4,101 & $(23.7)$ & 1,813 & & $(23.6)$ & \\
\hline No & 98,105 & $(76.9)$ & 79,000 & $(77.0)$ & 13,223 & $(76.3)$ & 5,882 & & $(76.4)$ & \\
\hline \multicolumn{10}{|l|}{ Dyslipidemia } & \multirow[t]{3}{*}{$<.0001$} \\
\hline Yes & 44,619 & (35.0) & 36,179 & (35.3) & 5,949 & (34.3) & 2,491 & & (32.4) & \\
\hline No & 82,954 & $(65.0)$ & 66,375 & $(64.7)$ & 11,375 & $(65.7)$ & 5,204 & & $(67.6)$ & \\
\hline \multicolumn{10}{|l|}{ Smoke } & \multirow[t]{2}{*}{0.0485} \\
\hline Yes & 20,004 & (15.7) & 16,205 & $(15.8)$ & 2,617 & (15.1) & 1,182 & & $(15.4)$ & \\
\hline \multicolumn{11}{|c|}{$\begin{array}{l}\text { *If there were missing values in Sex, Age, and Income deciles, we imputed them by closest ones from 2012. *If there was at least one in disease, we } \\
\text { regarded it as Yes. *In case of smoke, drink, and BMI, the values in } 2012 \text { were the criteria. If there were missing values in those variables, we imputed them } \\
\text { by the values in } 2011 .\end{array}$} \\
\hline
\end{tabular}




\begin{tabular}{|c|c|c|c|c|c|c|c|c|c|}
\hline No & 107,569 & $(84.3)$ & 86,349 & $(84.2)$ & 14,707 & (84.9) & 6,513 & $(84.6)$ & \\
\hline \multicolumn{9}{|l|}{ Drink } & \multirow[t]{3}{*}{$<.0001$} \\
\hline Yes & 47,178 & $(37.0)$ & 38,978 & $(38.0)$ & 5,776 & (33.3) & 2,424 & (31.5) & \\
\hline No & 80,395 & $(63.0)$ & 63,576 & $(62.0)$ & 11,548 & $(66.7)$ & 5,271 & $(68.5)$ & \\
\hline \multicolumn{9}{|l|}{ Body mass index $\left(\mathrm{kg} / \mathrm{m}^{2}\right)$} & \multirow[t]{3}{*}{0.0144} \\
\hline Mean & 23.97 & & 23.95 & & 24.04 & & 24.01 & & \\
\hline Standard deviation & 2.98 & & 2.95 & & 3.09 & & 3.19 & & \\
\hline \multicolumn{10}{|c|}{$\begin{array}{l}\text { *If there were missing values in Sex, Age, and Income deciles, we imputed them by closest ones from 2012. *If there was at least one in disease, we } \\
\text { regarded it as Yes. *In case of smoke, drink, and BMI, the values in } 2012 \text { were the criteria. If there were missing values in those variables, we imputed them } \\
\text { by the values in } 2011 .\end{array}$} \\
\hline \multicolumn{10}{|c|}{$\begin{array}{l}\star * \text { Group } 1=0 \leq \text { annual rate of height decrease } \varangle 0.3 \text {, Group } 2=0.3 \leq \text { annual rate of height decrease } \varangle 0.6 \text {, Group } 3=0.6 \geq \text { annual rate of height decrease, un } \\
(\mathrm{cm}) \text {. +Chi-square test or Kruskal-Wallis test. }\end{array}$} \\
\hline
\end{tabular}

\section{Outcomes And Height Loss Associations}

Table 2 presents the cumulative MACCE incidence based on the extent of the four-year height decrease. The cumulative MACCE incidence rates were $3.6 \%$ for Group 1, 4.5\% for Group 2, and 5.2\% for Group 3. The rates were $4.3 \%$ in Group 1, 5.0\% in Group 2, and 6.1\% in Group 3 among men, and $3.0 \%$ in Group $1,4.2 \%$ in Group 2, and $4.7 \%$ in Group 3 among women. 
Table 2

The cumulative adverse cardiovascular and cerebral event incidence rates per the annual height decrease rate

\begin{tabular}{|c|c|c|c|c|c|c|c|c|c|c|c|c|c|c|c|c|c|c|}
\hline & \multicolumn{6}{|l|}{ All } & \multicolumn{6}{|l|}{ Male } & \multicolumn{6}{|c|}{ Female } \\
\hline & \multicolumn{6}{|c|}{ Annual rate of height decrease ${ }^{\star \star}$} & \multicolumn{6}{|c|}{ Annual rate of height decrease $e^{\star \star}$} & \multicolumn{6}{|c|}{ Annual rate of height decrease $e^{\star \star}$} \\
\hline & \multicolumn{2}{|c|}{ Group 1} & \multicolumn{2}{|c|}{ Group 2} & \multicolumn{2}{|c|}{ Group 3} & \multicolumn{2}{|c|}{ Group 1} & \multicolumn{2}{|c|}{ Group 2} & \multicolumn{2}{|c|}{ Group 3} & \multicolumn{2}{|c|}{ Group 1} & \multicolumn{2}{|c|}{ Group 2} & \multicolumn{2}{|c|}{ Group 3} \\
\hline & \multicolumn{2}{|c|}{$(\mathrm{N}=102,554)$} & \multicolumn{2}{|c|}{$\begin{array}{l}(\mathrm{N}= \\
17,324)\end{array}$} & \multicolumn{2}{|c|}{$(N=7,695)$} & \multicolumn{2}{|c|}{$(\mathrm{N}=48,053)$} & \multicolumn{2}{|c|}{$(\mathrm{N}=6,780)$} & \multicolumn{2}{|c|}{$(\mathrm{N}=2,790)$} & \multicolumn{2}{|c|}{$(\mathrm{N}=54,501)$} & \multicolumn{2}{|c|}{$\begin{array}{l}(\mathrm{N}= \\
10,544)\end{array}$} & \multicolumn{2}{|c|}{$(\mathrm{N}=4,905$} \\
\hline $\begin{array}{l}\text { Accumulative } \\
\text { incidence rate }\end{array}$ & $\mathrm{n}$ & $(\%)$ & $\mathrm{n}$ & $(\%)$ & $\mathrm{n}$ & $(\%)$ & $\mathrm{n}$ & $(\%)$ & $\mathrm{n}$ & $(\%)$ & $\mathrm{n}$ & $(\%)$ & $\mathrm{n}$ & $(\%)$ & $\mathrm{n}$ & $(\%)$ & $\mathrm{n}$ & $(\%$ \\
\hline \multicolumn{19}{|l|}{ MACCE } \\
\hline 1st year & 892 & $(0.9)$ & 205 & $(1.2)$ & 95 & $(1.2)$ & 501 & $(1.0)$ & 97 & $(1.4)$ & 42 & $(1.5)$ & 391 & $(0.7)$ & 108 & $(1.0)$ & 53 & $(1$. \\
\hline 2nd year & 1,817 & $(1.8)$ & 391 & (2.3) & 183 & $(2.4)$ & 1,006 & (2.1) & 176 & $(2.6)$ & 78 & $(2.8)$ & 811 & $(1.5)$ & 215 & $(2.0)$ & 105 & (2. \\
\hline 3rd year & 2,696 & (2.6) & 580 & (3.4) & 295 & (3.8) & 1,473 & (3.1) & 255 & (3.8) & 124 & (4.4) & 1,223 & $(2.2)$ & 325 & (3.1) & 171 & (3. \\
\hline 4th year & 3,687 & (3.6) & 785 & $(4.5)$ & 401 & $(5.2)$ & 2,042 & $(4.3)$ & 338 & $(5.0)$ & 169 & (6.1) & 1,645 & (3.0) & 447 & $(4.2)$ & 232 & (4. \\
\hline Cardiac death & & & & & & & & & & & & & & & & & & \\
\hline 1st year & 24 & $(0.0)$ & 5 & $(0.0)$ & 6 & $(0.1)$ & 18 & $(0.0)$ & 3 & $(0.0)$ & 3 & $(0.1)$ & 6 & $(0.0)$ & 2 & $(0.0)$ & 3 & (0. \\
\hline 2nd year & 85 & $(0.1)$ & 12 & $(0.1)$ & 9 & $(0.1)$ & 58 & $(0.1)$ & 7 & $(0.1)$ & 6 & $(0.2)$ & 27 & $(0.1)$ & 5 & $(0.1)$ & 3 & $(0$. \\
\hline 3rd year & 149 & $(0.2)$ & 29 & $(0.2)$ & 23 & $(0.3)$ & 94 & $(0.2)$ & 16 & $(0.2)$ & 11 & $(0.4)$ & 55 & $(0.1)$ & 13 & $(0.1)$ & 12 & $(0$. \\
\hline 4th year & 245 & $(0.2)$ & 50 & $(0.3)$ & 42 & $(0.6)$ & 155 & $(0.3)$ & 27 & $(0.4)$ & 19 & $(0.7)$ & 90 & $(0.2)$ & 23 & $(0.2)$ & 23 & $(0$. \\
\hline Non-fatal MI & & & & & & & & & & & & & & & & & & \\
\hline 1st year & 114 & $(0.1)$ & 31 & $(0.2)$ & 10 & $(0.1)$ & 84 & $(0.2)$ & 20 & $(0.3)$ & 6 & $(0.2)$ & 30 & $(0.1)$ & 11 & $(0.1)$ & 4 & $(0$. \\
\hline 2nd year & 232 & $(0.2)$ & 52 & $(0.3)$ & 21 & $(0.3)$ & 159 & $(0.3)$ & 30 & $(0.4)$ & 12 & $(0.4)$ & 73 & $(0.1)$ & 22 & $(0.2)$ & 9 & $(0$. \\
\hline 3rd year & 365 & $(0.4)$ & 75 & $(0.4)$ & 36 & $(0.5)$ & 252 & $(0.5)$ & 44 & $(0.7)$ & 22 & $(0.8)$ & 113 & $(0.2)$ & 31 & $(0.3)$ & 14 & $(0$. \\
\hline 4th year & 504 & $(0.5)$ & 100 & $(0.6)$ & 51 & $(0.7)$ & 351 & $(0.7)$ & 55 & $(0.8)$ & 31 & (1.1) & 153 & $(0.3)$ & 45 & $(0.4)$ & 20 & (0. \\
\hline Stroke & & & & & & & & & & & & & & & & & & \\
\hline 1st year & 737 & $(0.7)$ & 171 & $(1.0)$ & 72 & $(0.9)$ & 394 & $(0.8)$ & 79 & $(1.2)$ & 30 & (1.1) & 343 & $(0.6)$ & 92 & $(0.9)$ & 42 & $(0$. \\
\hline 2nd year & 1,472 & (1.4) & 323 & (1.9) & 149 & (1.9) & 781 & $(1.6)$ & 140 & (2.1) & 60 & $(2.2)$ & 691 & (1.3) & 183 & (1.7) & 89 & (1. \\
\hline 3rd year & 2,154 & $(2.1)$ & 464 & $(2.7)$ & 227 & (3.0) & 1,122 & (2.3) & 193 & $(2.9)$ & 89 & (3.2) & 1,032 & (1.9) & 271 & (2.6) & 138 & (2. \\
\hline 4th year & 2,876 & $(2.8)$ & 620 & (3.6) & 296 & (3.9) & 1,520 & (3.2) & 255 & (3.8) & 116 & $(4.2)$ & 1,356 & $(2.5)$ & 365 & (3.5) & 180 & (3. \\
\hline $\begin{array}{l}\text { Hospitalization } \\
\text { for HF }\end{array}$ & & & & & & & & & & & & & & & & & & \\
\hline 1st year & 56 & $(0.1)$ & 11 & $(0.1)$ & 8 & $(0.1)$ & 35 & $(0.1)$ & 6 & $(0.1)$ & 3 & $(0.1)$ & 21 & $(0.0)$ & 5 & $(0.1)$ & 5 & $(0$. \\
\hline 2nd year & 116 & $(0.1)$ & 27 & $(0.2)$ & 14 & $(0.2)$ & 69 & $(0.1)$ & 17 & $(0.3)$ & 6 & $(0.2)$ & 47 & $(0.1)$ & 10 & $(0.1)$ & 8 & $(0$. \\
\hline 3rd year & 177 & $(0.2)$ & 47 & $(0.3)$ & 29 & $(0.4)$ & 103 & $(0.2)$ & 24 & $(0.4)$ & 11 & $(0.4)$ & 74 & $(0.1)$ & 23 & $(0.2)$ & 18 & $(0$. \\
\hline 4 th year & 270 & $(0.3)$ & 65 & $(0.4)$ & 42 & $(0.6)$ & 152 & $(0.3)$ & 28 & $(0.4)$ & 17 & $(0.6)$ & 118 & $(0.2)$ & 37 & $(0.4)$ & 25 & (0. \\
\hline
\end{tabular}

MACCE, major adverse cardiovascular and cerebral events; MI, myocardial infarction; $\mathrm{HF}$, heart failure.

* After observing the degrees of height reduction for 10 years form 2002, we annually calculated accumulative incidence rate of MACCE from Jan of 2012.

${ }^{\star}$ Group $1=0 \leq$ annual rate of height decrease $₫ 0.3$, Group2 $=0.3 \leq$ annual rate of height decrease $₫ 0.6$, Group3 $=0.6 \geq$ annual rate of height decrease, unit (cr

Figure 2 presents the Kaplan-Meier survival curves for the MACCE incidence rates based on the extent of height decrease. The cumulative MACCE incidence rate was highest in Group $3(\mathrm{HR}=1.46,95 \% \mathrm{Cl}=1.32-1.62)$, followed by Group 2 ( $\mathrm{HR}=1.27,95 \% \mathrm{Cl}=1.17-1.37$ ) and Group 1 (Reference); the inter-group difference was significant $(\mathrm{p}<0.0001)$. All of the MACCE components, including cardiac death $(\mathrm{HR}=2.29,95 \% \mathrm{Cl}=1.65-3.17)$, non-fatal $\mathrm{Ml}(\mathrm{HR}=1.35,95 \% \mathrm{Cl}$ $=1.01-1.80)$, and stroke $(\mathrm{HR}=1.38,95 \% \mathrm{Cl}=1.22-1.55)$ occurred more frequently in Group 3 than in Group 1.

Table 3 presents the Cox proportional-hazard model results for the annual height decrease rate and MACCE incidences. In the crude model, the MACCE and cardiac death risks were 1.46 times and 2.29 times higher in Group 3 than in Group 1, respectively, and the inter-group difference was significant considering the $95 \% \mathrm{Cl}$. In the adjusted model, the risks of MACCE (1.25 times), cardiac death (1.67 times), stroke (1.18 times), and hospitalization for HF (1.56 times) were higher in Group 3 than in Group 1; the inter-group difference was significant. The subgroup analysis of the elderly population (age $\geq 60$ years) demonstrated similar results (Supplementary Tables 1 and 2). In women, height loss increases dramatically after menopause. The analysis of premenopausal versus 
menopausal groups demonstrated that MACCE rarely occurred in premenopausal women (Supplementary Tables 3 and 4), and height loss was significantly associated with MACCE in postmenopausal women (age $\geq 50$ years).

Table 3

Hazard ratios of adverse cardiovascular and cerebral events per the annual height decrease rate

\begin{tabular}{|c|c|c|c|c|c|}
\hline \multirow[b]{3}{*}{ Cardiovascular disease } & \multicolumn{5}{|c|}{ Annual rate of height decrease $e^{\star \star}$} \\
\hline & \multirow{2}{*}{$\begin{array}{l}\text { Group } 1 \\
\text { (ref.) }\end{array}$} & \multicolumn{2}{|l|}{ Group 2} & \multicolumn{2}{|c|}{ Group 3} \\
\hline & & $\mathrm{HR}$ & $95 \% \mathrm{Cl}$ & $\mathrm{HR}$ & $95 \% \mathrm{Cl}$ \\
\hline \multicolumn{6}{|l|}{ Crude model } \\
\hline MACCE & 1 & 1.27 & $1.17,1.37$ & 1.46 & $1.32,1.62$ \\
\hline Cardiac death & 1 & 1.21 & $0.89,1.64$ & 2.29 & $1.65,3.17$ \\
\hline Non-fatal MI & 1 & 1.18 & $0.95,1.46$ & 1.35 & $1.01,1.80$ \\
\hline Stroke & 1 & 1.28 & $1.18,1.40$ & 1.38 & $1.22,1.56$ \\
\hline Hospitalization for HF & 1 & 1.43 & $1.09,1.87$ & 2.08 & $1.50,2.87$ \\
\hline \multicolumn{6}{|l|}{ Adjusted model* } \\
\hline MACCE & 1 & 1.11 & $1.07,1.20$ & 1.25 & $1.13,1.39$ \\
\hline Cardiac death & 1 & 0.96 & $0.71,1.30$ & 1.67 & $1.20,2.33$ \\
\hline Non-fatal MI & 1 & 1.12 & $0.90,1.39$ & 1.30 & $0.97,1.73$ \\
\hline Stroke & 1 & 1.12 & $1.02,1.22$ & 1.18 & $1.04,1.33$ \\
\hline Hospitalization for HF & 1 & 1.15 & $0.88,1.51$ & 1.56 & $1.12,2.17$ \\
\hline \multicolumn{6}{|c|}{ MACCE, major adverse cardiovascular and cerebral events; MI, myocardial infarction; HF, heart failure. } \\
\hline \multicolumn{6}{|c|}{ *sex, age, income deciles, diabetes, dyslipidemia, osteoporosis, hypertension, smoke, drink and body mass index were interpolated. } \\
\hline \multicolumn{6}{|c|}{$\begin{array}{l}\star^{*} \text { Group } 1=0 \leq \text { annual rate of height decrease } \varangle 0.3, \text { Group } 2=0.3 \leq \text { annual rate of height decrease } \varangle 0.6 \text {, Group } 3=0.6 \geq \text { annual rate of height decrease, uni } \\
(\mathrm{cm}) .\end{array}$} \\
\hline
\end{tabular}

\section{Height Loss Determinants}

Supplementary Fig. 1 presents the multiple logistic regression results on the demographic and clinical characteristics and the height decrease per group. The analysis of variables that affect height decreases showed that the annual height decrease rate in women versus men was 1.37 times higher in Group 2 than Group 1 and 1.55 times higher in Group 3 than Group $1(p<0.0001)$. Other significant variables affecting the height decrease rate included age, income deciles, hypertension, osteoporosis, and menopause $(p<0.0001)$. Diabetes, dyslipidemia, smoking, drinking, BMI, and baseline height did not affect the height decrease rate, or the rates were lower in Groups 2 and 3 than in Group 1.

\section{Discussion}

This study analyzed 127573 subjects from the Korean NHIS database and found that degree of height loss was independently associated with an increased risk of MACCE, defined as cardiac death, non-fatal MI, unplanned hospitalization for HF, or stroke. Subgroups analyses of the elderly (age $\geq 60$ years) and postmenopausal women (age $\geq 50$ years), both of which have more height decline, also demonstrated this association (Supplementary Table 1-4). Subjects with the most height decline (i.e., $\geq 0.6 \mathrm{~cm} /$ year) had significantly worse event-free survival for MACCE compared to subjects with lesser degrees of height loss. Height loss determinants included age, sex, menopausal status, and income level. These results are in parallel with the British data published approximately two decades ago and support the hypothesis that height loss is not simply a common aging process but is also independently correlated with CVD occurrences and may be a modifiable risk factor.

\section{The Height Loss Mechanism and CVD Associations}

The inverse relationship between adult height and CVD has been repeatedly reported in epidemiological investigations. However, a single theory cannot explain the mechanism for the phenomenon. We and others claimed that dyslipidemia, arterial stiffening represented by a higher pulse wave velocity or diastolic dysfunction of the heart would serve as a link between shortness and CVD occurrences and outcomes. ${ }^{13-17}$ Further, the association mechanism between height decreases and CVD is also unclear. However, it might differ from the theory that adult height is a risk CVD factor. An individual's maximum height is genetically determined and a non-modifiable factor. Conversely, height loss resulting from senile bone, muscles, and joints changes, is affected by environmental and personal factors and might be modifiable. Pathophysiology for osteoporosis and sarcopenia is poorly understood and likely multifactorial, but some factors can be targeted for intervention, such as physical inactivity, alcoholism, tobacco use, vitamin D deficiency, or an unhealthy diet. Osteoporosis, characterized by a reduction of bone density and increased fracture risk, is the primary contributor to height loss by reducing vertebral body 
strength and inducing the loss of mineral content and trabecular connectivity. Notably, a decrease in stature from osteoporosis and fracture is often remarkable and is likely to reach several centimeters. ${ }^{10,18} \mathrm{CVD}$ and osteoporosis, which often coexist, are public health problems with multiple epidemiological links, pathophysiological mechanisms, and economic consequences. ${ }^{19-22}$ Studies have demonstrated that CVD and cardiovascular mortality are associated with reduced bone mineral density and bone fractures. Additionally, sarcopenia and poor muscle strength, occurring as part of the aging process, are associated with bone loss and diseased bone structure, eventually resulting in height loss. Osteoporosis and sarcopenia are known predictors of mortality and are preventable and treatable conditions, theoretically, with environmental modifications and medical interventions. ${ }^{9}$

\section{Presumable Rationale of the Adverse Effect of Height Loss for CVD}

The basis for mechanisms relating to height loss and subsequent CVD remains unclear. However, the effect of height loss, which is a predictor of vertebral fracture, on the respiratory and gastrointestinal systems is noteworthy. Vertebral fractures induce thoracic deformity and pain and disturb pulmonary function. Conversely, percutaneous vertebroplasty and kyphoplasty for vertebral fractures improve lung function. Further, lung capacity and gastrointestinal function decrease as height decline, potentially leading to less exercise, effort intolerance, early satiety, and poor nutritional status, resulting in sarcopenia and senile fragility. ${ }^{23-28}$ Weight loss and leanness, attributed to the loss of skeletal muscle mass in the elderly, are known risk factors for CVD (the so-called "obesity paradox"). ${ }^{29-32}$ Moreover, a musculoskeletal deformity has a significant effect on psychological problems, such as depression and anxiety and the quality of life. From that perspective, a height decline might play a causative role in CVD occurrence. However, bone loss and poor bone quality (important determinants of height decline) share common pathophysiological mechanisms with CVD, such as oxidative stress, inflammation, abnormal homocysteine levels, and metabolic risk factors (i.e., hypertension, diabetes, and dyslipidemia). ${ }^{33}$ Considering this, height loss would be a co-finding of CVD rather than a primary cause.

\section{Study Strengths And Limitations}

The current investigation was performed based on KCD-7. Thus, biomarkers that are known cardiovascular risk factors, such as laboratory findings, were not available for analysis. Further, data on each patients' medication history was unavailable. The main contributor to height loss is osteoporosis, but we were unable to objectively assess each subject's bone mass density beyond the KCD-7 code. However, the foremost strength of the current epidemiologic study using an anthropometric parameter is the large sample size. Our study sample homogeneity is also noteworthy as all data were gathered in one country in a relatively short time frame (ten years of height monitoring and two years of outcome surveillance), and the analysis included one ethnicity. Adult height and height loss are influenced by many factors. Thus, the effects of confounders, such as race and socioeconomic status, are minimized.

\section{Conclusions}

The degree of height loss was independently associated with the occurrence of MACCE in a Korean population. However, a causal or a co-finding relationship between the two has yet to be determined.

\section{Declarations}

Ethics approval and consent to participate: The Data provision review committee of National Health Insurance Service (Study Management No. NHIS-2020-2099) and the Institutional Review Board of Gachon University Gil Medical Center (IRB No. GFIRB2019-304) approved this study before commencement. Because this study was conducted using a sample cohort database provided by the NHIS (NHIS-National Sample Cohort), the Institutional Review Board of Gachon University Gil Medical Center waived informed consent. This study was performed in accordance with the relevant guidelines and regulations.

Consent for publication: Not applicable.

Availability of data and materials: Restrictions apply to the availability of these raw data, which were used under a policy of NHIS. The data and materials other than raw data underling the study are available from the corresponding author, Dr. Woong Chol Kang, on reasonable request.

Competing interests: The authors declare that they have no competing interests.

\section{Funding: None}

Authors' contributions: J.G. and W.C. designed the study and prepared the manuscript as submitted. J.G. analyzed and interpreted the data. W.C. supervised the project. All authors reviewed and critically revised the manuscript. The author(s) read and approved the final manuscript.

Acknowledgments: We would like to thank Research Institute of The Way Health Care, Seoul, the Republic of Korea, for the statistical analyses and Editage (www.editage.co.kr) for English language editing.

\section{References}

1. Silventoinen K, Zdravkovic S, Skytthe A, et al. Association between height and coronary heart disease mortality: a prospective study of 35,000 twin pairs. Am J Epidemiol. Apr 1 2006;163(7):615-21. doi:10.1093/aje/kwj081

2. Nelson CP, Hamby SE, Saleheen D, et al. Genetically determined height and coronary artery disease. N Engl J Med. Apr 23 2015;372(17):1608-18. doi:10.1056/NEJMoa1404881

3. Park CS, Choi EK, Han KD, et al. Association between adult height, myocardial infarction, heart failure, stroke and death: a Korean nationwide populationbased study. Int J Epidemiol. Feb 1 2018;47(1):289-298. doi:10.1093/ije/dyx175

Page $8 / 11$ 
4. Park YM, Moon J, Hwang IC, Lim H, Cho B. Short stature is associated with incident sudden cardiac death in a large Asian cohort. Heart Rhythm. Jun 2020;17(6):931-936. doi:10.1016/j.hrthm.2020.01.026

5. Solomons NW. Vision of Research on Human Linear Growth. Food Nutr Bull. Dec 2019;40(4):416-431. doi:10.1177/0379572119885475

6. Sorkin JD, Muller DC, Andres R. Longitudinal change in height of men and women: implications for interpretation of the body mass index: the Baltimore Longitudinal Study of Aging. Am J Epidemiol. Nov 1 1999;150(9):969-77. doi:10.1093/oxfordjournals.aje.a010106

7. Szulc P, Beck TJ, Marchand F, Delmas PD. Low skeletal muscle mass is associated with poor structural parameters of bone and impaired balance in elderly men-the MINOS study. J Bone Miner Res. May 2005;20(5):721-9. doi:10.1359/JBMR.041230

8. Old JL, Calvert M. Vertebral compression fractures in the elderly. Am Fam Physician. Jan 1 2004;69(1):111-6.

9. Metter EJ, Talbot LA, Schrager M, Conwit R. Skeletal muscle strength as a predictor of all-cause mortality in healthy men. J Gerontol A Biol Sci Med Sci. Oct 2002;57(10):B359-65. doi:10.1093/gerona/57.10.b359

10. Wannamethee SG, Shaper AG, Lennon L, Whincup PH. Height loss in older men: associations with total mortality and incidence of cardiovascular disease. Arch Intern Med. Dec 11-25 2006;166(22):2546-52. doi:10.1001/archinte.166.22.2546

11. Lee YH, Han K, Ko SH, Ko KS, Lee KU, Taskforce Team of Diabetes Fact Sheet of the Korean Diabetes A. Data Analytic Process of a Nationwide Population-Based Study Using National Health Information Database Established by National Health Insurance Service. Diabetes Metab J. Feb 2016;40(1):79-82. doi:10.4093/dmj.2016.40.1.79

12. Lim HS, Kim TH, Lee HH, Park YH, Kim JM, Lee BR. Hypertension and age at onset of natural menopause in Korean postmenopausal women: Results from the Korea National Health and Nutrition Examination Survey (2008-2013). Maturitas. Aug 2016;90:17-23. doi:10.1016/j.maturitas.2016.04.019

13. Moon J, Lee HJ, Kim YJ, et al. Short stature and ischemic stroke in nonvalvular atrial fibrillation: new insight into the old observation. Int $\mathrm{J}$ Cardiol. Jul 1 2014;174(3):541-4. doi:10.1016/j.ijcard.2014.04.154

14. Moon J, Suh J, Oh PC, et al. Relation of Stature to Outcomes in Korean Patients Undergoing Primary Percutaneous Coronary Intervention for Acute STElevation Myocardial Infarction (from the INTERSTELLAR Registry). Am J Cardiol. Jul 15 2016;118(2):177-82. doi:10.1016/j.amjcard.2016.04.046

15. Moon J, Hwang IC, Han SH. Short stature is associated with higher pulse wave velocity in subjects without overt cardiovascular disease. Medicine (Baltimore). Sep 25 2020;99(39):e22219. doi:10.1097/MD.0000000000022219

16. Hwang IC, Park YM, Kang WC, Moon J. Association between height and lipid profile among Korean men: results from the 10-year Korea National Health and Nutrition Examination Survey. Eur J Prev Cardiol. Dec 2020;27(19):2205-2207. doi:10.1177/2047487319877055

17. Hwang IC, Park YM, Kang WC, Moon J. Height Is Associated with Dyslipidemia in Korean Premenopausal Women: Data from the Korea National Health and Nutrition Examination Survey. Cardiology. 2020;145(11):736-739. doi:10.1159/000509631

18. Siminoski K, Warshawski RS, Jen H, Lee K. The accuracy of historical height loss for the detection of vertebral fractures in postmenopausal women. Osteoporos Int. Feb 2006;17(2):290-6. doi:10.1007/s00198-005-2017-y

19. Farhat GN, Cauley JA. The link between osteoporosis and cardiovascular disease. Clin Cases Miner Bone Metab. Jan 2008;5(1):19-34.

20. Crepaldi G, Maggi S. Epidemiologic link between osteoporosis and cardiovascular disease. J Endocrinol Invest. 2009;32(4 Suppl):2-5.

21. McFarlane SI, Muniyappa R, Shin JJ, Bahtiyar G, Sowers JR. Osteoporosis and cardiovascular disease: brittle bones and boned arteries, is there a link? Endocrine. Feb 2004;23(1):1-10. doi:10.1385/END0:23:1:01

22. Whitney C, Warburton DE, Frohlich J, Chan SY, McKay H, Khan K. Are cardiovascular disease and osteoporosis directly linked? Sports Med. 2004;34(12):779-807. doi:10.2165/00007256-200434120-00001

23. Lombardi I, Jr., Oliveira LM, Mayer AF, Jardim JR, Natour J. Evaluation of pulmonary function and quality of life in women with osteoporosis. Osteoporos Int. Oct 2005;16(10):1247-53. doi:10.1007/s00198-005-1834-3

24. Kjensli A, Falch JA, Ryg M, et al. High prevalence of vertebral deformities in COPD patients: relationship to disease severity. Eur Respir J. May 2009;33(5):1018-24. doi:10.1183/09031936.00073908

25. Leech JA, Dulberg C, Kellie S, Pattee L, Gay J. Relationship of lung function to severity of osteoporosis in women. Am Rev Respir Dis. Jan 1990;141(1):68-71. doi:10.1164/ajrccm/141.1.68

26. Ross PD, Davis JW, Epstein RS, Wasnich RD. Pain and disability associated with new vertebral fractures and other spinal conditions. J Clin Epidemiol. Mar 1994;47(3):231-9. doi:10.1016/0895-4356(94)90004-3

27. Ross PD. Clinical consequences of vertebral fractures. Am J Med. Aug 18 1997;103(2A):30S-42S; discussion 42S-43S. doi:10.1016/s00029343(97)90025-5

28. Yuan HA, Brown CW, Phillips FM. Osteoporotic spinal deformity: a biomechanical rationale for the clinical consequences and treatment of vertebral body compression fractures. J Spinal Disord Tech. Jun 2004;17(3):236-42. doi:10.1097/00024720-200406000-00012

29. Hughes VA, Frontera WR, Roubenoff R, Evans WJ, Singh MA. Longitudinal changes in body composition in older men and women: role of body weight change and physical activity. Am J Clin Nutr. Aug 2002;76(2):473-81. doi:10.1093/ajcn/76.2.473

30. Carnethon MR, De Chavez PJ, Biggs ML, et al. Association of weight status with mortality in adults with incident diabetes. JAMA. Aug 8 2012;308(6):58190. doi:10.1001/jama.2012.9282

31. Logue J, Walker JJ, Leese G, et al. Association between BMI measured within a year after diagnosis of type 2 diabetes and mortality. Diabetes Care. Apr 2013;36(4):887-93. doi:10.2337/dc12-0944

32. Pischon T, Boeing H, Hoffmann K, et al. General and abdominal adiposity and risk of death in Europe. N Engl J Med. Nov 13 2008;359(20):2105-20. doi:10.1056/NEJMoa0801891

Page $9 / 11$ 
33. Laroche M, Pecourneau V, Blain H, et al. Osteoporosis and ischemic cardiovascular disease. Joint Bone Spine. Jul 2017;84(4):427-432. doi:10.1016/j.jbspin.2016.09.022

\section{Figures}

\begin{tabular}{|c|c|}
\hline $\begin{array}{l}\text { Total patients extracted from NIHSS sample cohort data } \\
\qquad(\mathrm{N}=332,579)\end{array}$ & \multirow[b]{2}{*}{ Excluded $(\mathrm{N}=205,006)$} \\
\hline & \\
\hline & Unable to measure heights or measured only one time $(\mathrm{N}=89,194)$ \\
\hline & Outliers* in heights $(\mathrm{N}=57,164)$ \\
\hline & Missing values in drinking, smoking, income quantiles, $\mathrm{BMI}(\mathrm{N}=689)$ \\
\hline & Occurred MACE during $2002 \sim 2011(\mathrm{~N}=27,599)$ \\
\hline & Died before $2012(\mathrm{~N}=30,360)$ \\
\hline
\end{tabular}

Analysis population $(\mathrm{N}=127,573)$

\begin{tabular}{|c|c|}
\hline \multicolumn{2}{|c|}{ Group allocation } \\
\hline$\left[\begin{array}{c}\text { Group 1 } \\
{[0 \leq \text { Annual rate of height decrease }} \\
\left.(\mathrm{cm})^{* *}<0.3\right]\end{array}\right.$ & $\mathrm{N}=102,554$ \\
\hline $\begin{array}{c}\text { Group 2 } \\
{[0.3 \leq \text { Annual rate of height decrease }} \\
\left.(\mathrm{cm})^{* *}<0.6\right]\end{array}$ & $\mathrm{N}=17,324$ \\
\hline $\begin{array}{c}\text { Group 3 } \\
{\left[\text { Annual rate of height decrease }(\mathrm{cm})^{* *} \geq 0.6\right]}\end{array}$ & $\mathrm{N}=7,695$ \\
\hline
\end{tabular}

\section{Figure 1}

A flow diagram of the study population 

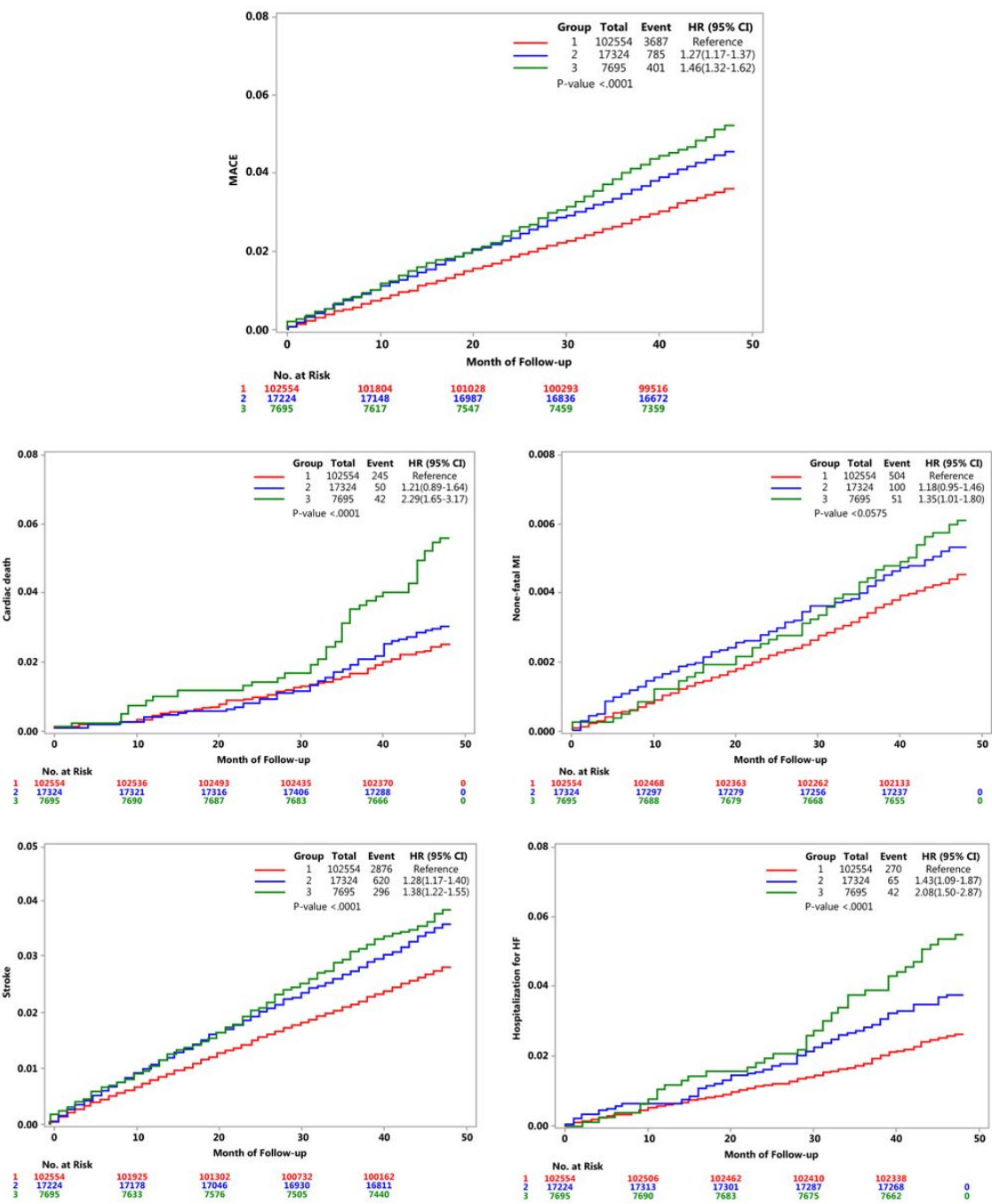

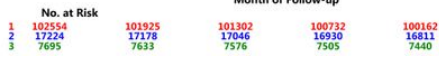

Figure 2

Kaplan-Meier curves for major adverse cardiovascular and cerebral events

\section{Supplementary Files}

This is a list of supplementary files associated with this preprint. Click to download.

- Sfigure1.jpg

- STable1.docx

- STable2.docx

- STable3.docx

- STable4.docx 